\title{
MIGRACIÓN, EDUCACIÓN Y MARGINALIDAD EN LA CIUDAD DE MÉXICO*
}

\author{
Claudio Stern** \\ El Colegio de México
}

\section{INTRODUCCIÓN}

LOS RESULTADOS de investigaciones anteriores sobre migración y marginalización tienden a mostrar que es posible diagnosticar un proceso de marginalización ocupacional creciente en la ciudad de México y que ésta recae predominantemente en sectores de población que han migrado recientemente hacia la misma. ${ }^{1}$

Independientemente de que la explicación de este proceso como tal requiera de la consideración de una multiplicidad de factores vinculados con el proceso global de desarrollo, uno de los elementos que podría entrar en la misma está constituído por posibles modificaciones en el grado relativo de calificación de la fuerza de trabajo migrante. Es únicamente sobre este factor sobre el cual centraremos nuestra atención.

Bajo el supuesto de que sea correcta la inferencia derivada de nuestros trabajos anteriores, en el sentido de que una proporción creciente de los individuos que migran al área metropolitana de la ciudad de México encuentra dificultades para ubicarse de manera "adecuada" en el mercado de trabajo urbano, aquí se explora la posibilidad de que

* Versión modificada del trabajo presentado a la IV reunión del Grupo de Trabajo sobre Migraciones Internas de la Comisión de Población y Desarrollo del Consejo Latinoamericano de Ciencias Sociales, celebrada en Bogotá, Colombia, del 17 al 21 de diciembre de 1973 y el cual forma parte del proyecto de investigación sobre "Migración interna, estructura ocupacional y movilidad social en la ciudad de México", que se lleva a cabo en el Centro de Estudios Económicos y Demográficos en colaboración con el Centro de Estudios Sociológicos de El Colegio de México y el Instituto de Investigaciones Sociales de la Universidad Nacional Autónoma de México.

** Agradezco los comentarios recibidos por parte de los asistentes a la reunión citada, así como los de Gustavo Cabrera, Rodolfo Stavenhagen y Jorge Padua de El Colegio de México y de Enrique Contreras del Instituto de Investigaciones Sociales de la UNAM, los cuales he intentado incorporar en estar versión.

1 Véase especialmente Humberto Muñoz, Orlandina de Oliveira y Claudio Stern, "Migración y marginalidad ocupacional en la ciudad de México", en El perfil de México en 1980, Vol. 3. México, Siglo xxI Editores, 1972, pp. 325-358, así como el estudio de Enrique Contreras incluído en el mismo volumen. 
este hecho pueda relacionarse con ciertos cambios en los orígenes regionales y comunales de la población que ha migrado hacia la ciudad capital.

Concretamente, se propone la hipótesis de que proporciones crecientes de migrantes hacia la ciudad de México provienen, por una parte, de localidades rurales y, por otra, de zonas "atrasadas". Ambos factores, dados los desequilibrios regionales y las diferencias rural-urbanas existentes en México, así como la ampliación de los mismos en los últimos decenios, permiten inferir una segunda hipótesis: que se hayan ampliado las diferencias entre los niveles de instrucción de los migrantes que viven en la capital y los nativos de la misma y que, por tanto, disminuye su grado de competitividad en términos de oportunidades ocupacionales, dado un aumento en los requerimientos formales para ingresar a la fuerza de trabajo. ${ }^{2}$

En este sentido, se presentan aquí algunos datos derivados de una exploración recién iniciada para poner a prueba estas hipótesis. ${ }^{3}$

En primer lugar, se describen algunas tendencias observadas en términos de cambios en los orígenes regionales de los migrantes que viven en el área metropolitana (1970) según su período de llegada. ${ }^{4}$ Se analizan después las diferencias encontradas en cuanto a los orígenes de las diversas cohortes de migrantes por tamaño de la localidad y nivel de desarrollo socioeconómico de la zona de nacimiento. Posteriormente, se muestra la asociación existente entre el nivel de instrucción de la población y las dos variables anteriores para mostrar, por último, cómo han variado los niveles de instrucción entre diferentes cohortes de migrantes según el período de su llegada a la ciudad de México.

\section{ORÍGENES REgIONALES POR COHORTES DE LLEGADA}

En el cuadro 1 pueden verse los origenes regionales ${ }^{5}$ de los habitantes de la ciudad de México no nacidos en ella, los cuales constituyen el $36 \%$ de la población total y más del $50 \%$ de la población adulta.

Puede observarse que cerca del $90 \%$ de la población migrante proviene de las regiones más cercanas a la capital (las primeras cuatro; véase el mapa 1). Una tercera parte de la región centro-oriente, que comprende las entidades federativas que circundan a la ciudad: México, Morelos, Puebla, Hidalgo y Tlaxcala, otra tercera parte de los

2 Respecto a las diferencias regionales y rural-urbanas en cuanto a educación, véase Adolfo Mir Araujo, Ecological Inequalities in Educational Attainment in Mexico, tesis doctoral, Universidad de Texas en Austin, enero de 1970.

3 En el apéndice metodológico se describe de manera breve la naturaleza de los datos y las téenicas utilizadas.

4 Denominaremos a los migrantes que llegaron en los diferentes períodos "cohortes de llegada" o "cohortes de migrantes" indistintamente.

5 Para el presente análisis se utiliza la regionalización geográfico-económica propuesta por Claude Bataillon, Las regiones geográficas de México, México, Siglo xxI Editores, 1969. 
Cuadro 1

Orígenes regronales de los migrantes internos a la ciudad de México POR COHORTES DE LLEGADA

(Porcientos)

\begin{tabular}{|c|c|c|c|c|c|c|}
\hline \multirow{2}{*}{ Rogion } & \multicolumn{5}{|c|}{ Cohorte do llogada a la ciudad de Méxioo } & \multirow{2}{*}{ Total } \\
\hline & $\begin{array}{c}\text { Antes } \\
\text { do } 1935\end{array}$ & $\begin{array}{l}1935- \\
1944\end{array}$ & $\begin{array}{l}1945- \\
1954\end{array}$ & $\begin{array}{l}1955- \\
1964\end{array}$ & $\begin{array}{l}1965- \\
1970\end{array}$ & \\
\hline Centro-oriente & 46.6 & 34.1 & 36.4 & $34 \cdot 4$ & 30.8 & 35.7 \\
\hline Poriferia arbanizada & 29.5 & 35.4 & 34.1 & 34.9 & 34.9 & 34.1 \\
\hline Periferta no urbanizada & 4.2 & 6.4 & 11.7 & 9.0 & 15.0 & 9.9 \\
\hline Centro-oocidente & 10.4 & 12.4 & 3.5 & 10.0 & 8.4 & 9.9 \\
\hline Noroeste te & 1.8 & 3.2 & 1.7 & 3.4 & 4.3 & 3.0 \\
\hline Norte-Noreste & 5.1 & 4.5 & 2.7 & 4.9 & 2.9 & 4.0 \\
\hline Sureste & 2.4 & 4.0 & 3.8 & 3.4 & 3.6 & 3.5 \\
\hline $\begin{array}{l}\text { Proporción representada } \\
\text { por la cohorte }\end{array}$ & 13.8 & 12.2 & 21.1 & 30.5 & 22.4 & 100.0 \\
\hline $\begin{array}{l}\text { Ninero do oasos on la } \\
\text { muss tra original }\end{array}$ & $(6.7)$ & (535) & $(895)$ & $\left(\begin{array}{ll}1 & 284\end{array}\right)$ & $(988)$ & (4 319) \\
\hline
\end{tabular}

Fuente: Muestra representativa ponderada.

estados que forman la periferia urbanizada de la ciudad: Guanajuato, Michoacán, Querétaro, San Luis Potosí y Veracruz. Las dos regiones que le siguen en importancia numérica son la centro-occidente formada por los estados de Jalisco, Colima, Nayarit, Aguascalientes y Zacatecas, con el $10 \%$, y la periferia no urbanizada que se encuentra hacia el sur de la ciudad capital y que comprende los estados de Guerrero y Oaxaca, con otro $10 \%$. Las tres regiones más alejadas: la noroeste, la norte-noreste y la sureste, contribuyen con menos del $4 \%$ cada una a la población migrante de la capital.

Aparte de factores tales como la distancia, una razón importante que explica parcialmente la alta preponderancia de la migración cercana en especial a partir de la región centro-oriental es la ancestral elevada densidad de población de dichas regiones. ${ }^{6}$

Para el análisis que pretendemos llevar a cabo, la pregunta de si se han dado cambios significativos en los orígenes regionales de diversas cohortes de migrantes a la ciudad de México es fundamental. Como puede verse en el cuadro 1, se registran variaciones importantes: las tendencias más claras y significativas consisten, por una parte, en una disminución proporcional de los flujos provenientes de la región centrooriente (de $46.6 \%$ para la cohorte que llegó a la capital antes de 1935, a $30.8 \%$ para la que llegó entre 1965 y 1970), que se "compensa" por la proporción creciente de migrantes que provienen de la periferia no

6 Obviamente las altas tasas de emigración a partir de dichas regiones no se deben a la densidad misma, pero como bien lo establece Claude Bataillon, en La ciudad y el campo en el México central, México, Siglo xxi Editores, 1972, ésta se constituye en un factor ecológico de suma importancia, dadas ciertas características del proceso de desarrollo. 


\section{Mapa 1}

Regiones geográficas de México

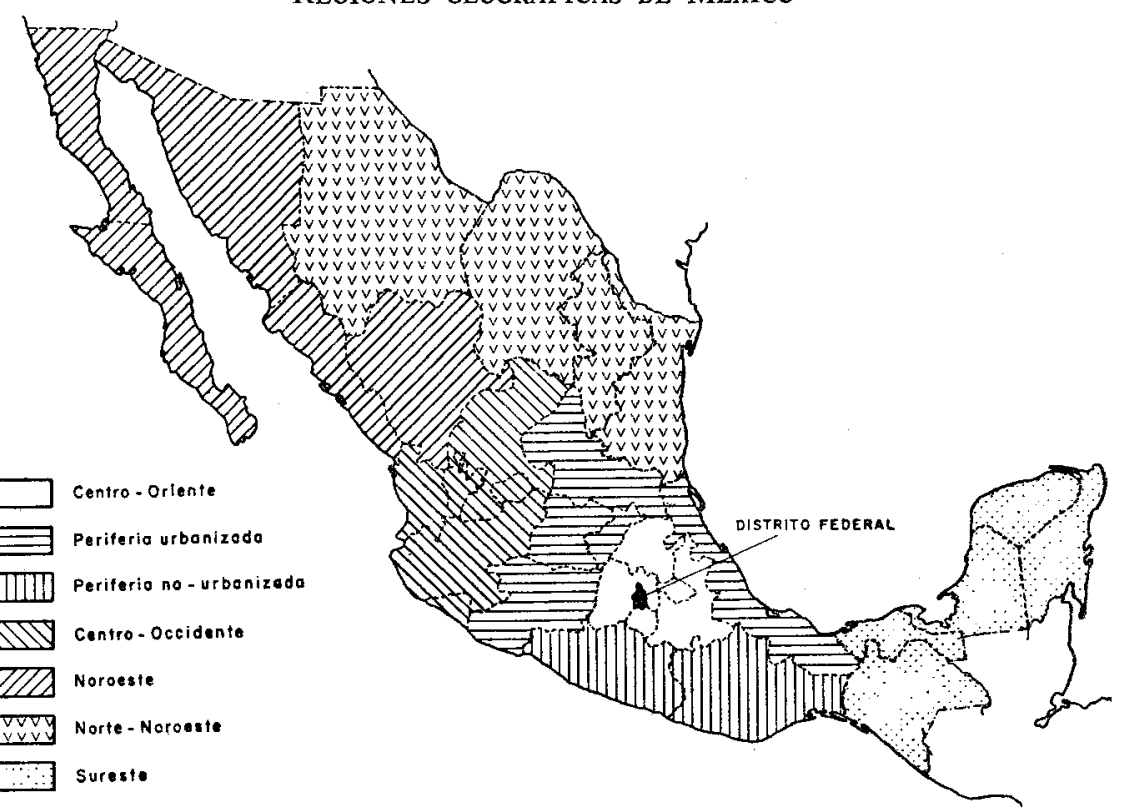

urbanizada (de $4.2 \%$ para la primera cohorte de llegada a $15.0 \%$ para la más reciente). La proporción de migrantes que provienen de la periferia urbanizada ha permanecido más o menos constante -alrededor de una tercera parte-; las variaciones entre las cantidades de migrantes que provienen de las regiones restantes no son muy significativas.

Antes de preguntarnos qué significan las principales tendencias observadas, conviene echar un vistazo a lo sucedido en cuanto a las entidades federativas que forman estas grandes regiones.

En la región centro-oriente la disminución más notable corresponde a la población proveniente del estado de México, el cual disminuye su contribución de migrantes de $23 \%$ a $9 \%$ (véase el cuadro 2). Entre las demás entidades de la región, Hidalgo y Puebla -las más atrasadas entre las que la conforman ${ }^{\top}{ }^{\top}$ aumentan ligeramente su participación y disminuye un poco o permanece más o menos estable en los casos de Morelos y Tlaxcala. En otras palabras, la disminución de la población migrante de la región centro-oriente se debe principalmente a la acaecida en relación al estado de México.

Respecto a la región periférica urbanizada, el comportamiento mi-

7 Véase su rango de desarrollo socioeconómico entre las 32 entidades federativas que conforman el país, en el cuadro 2 . 


\section{Cuadro 2}

TENDENCIAS MIGRATORIAS POR ENTIDADES FEDERATIVAS Y REGIONES, POR COHORTES DE LLEGAdA A LA CIUdAd DE MÉXICO, 1970

(Porcientos)

\begin{tabular}{|c|c|c|c|c|}
\hline \multirow[b]{2}{*}{$\begin{array}{l}\text { Region y entidad } \\
\text { federativa }\end{array}$} & \multirow{2}{*}{ Riangog/ } & \multicolumn{3}{|c|}{ Cohorte de Ilegada } \\
\hline & & $\begin{array}{l}\text { Antes } \\
\text { do } 1935\end{array}$ & $\begin{array}{l}1935- \\
1954\end{array}$ & $\begin{array}{l}1955- \\
1970\end{array}$ \\
\hline Centro-oriente & & 46.3 & 35.6 & 33.0 \\
\hline $\begin{array}{l}\text { Hidalgg } \\
\text { Maxiog } \\
\text { Moreloa } \\
\text { Puobla } \\
\text { Thaxoala }\end{array}$ & $\begin{array}{l}28 \\
20 \\
10 \\
25 \\
22\end{array}$ & $\begin{array}{r}8.9 \\
23.3 \\
2.1 \\
8.5 \\
3.6\end{array}$ & $\begin{array}{r}9.7 \\
12.6 \\
1.8 \\
9.2 \\
2.3\end{array}$ & $\begin{array}{r}10.0 \\
9.4 \\
1.9 \\
9.3 \\
2.4\end{array}$ \\
\hline Periferla urbanizada & & 29.9 & 34.7 & 34.9 \\
\hline $\begin{array}{l}\text { Guana jua to } \\
\text { Michoaoan } \\
\text { Querétaro } \\
\text { San Luig Potosi } \\
\text { Veraoruz }\end{array}$ & $\begin{array}{l}21 \\
26 \\
27 \\
23 \\
17\end{array}$ & $\begin{array}{r}12.2 \\
7.3 \\
4.0 \\
1.7 \\
4.7\end{array}$ & $\begin{array}{r}12.3 \\
10.4 \\
4.0 \\
1.7 \\
6.3\end{array}$ & $\begin{array}{r}8.7 \\
1.3 .6 \\
1.6 \\
3.9 \\
7.1\end{array}$ \\
\hline Periferia no urbenizada & & 4.3 & 9.7 & 31.6 \\
\hline $\begin{array}{l}\text { Guerrero } \\
\text { Oaraca }\end{array}$ & $\begin{array}{l}30 \\
32\end{array}$ & $\begin{array}{l}1.8 \\
1.5\end{array}$ & $\begin{array}{l}3.4 \\
6: 3\end{array}$ & $\begin{array}{l}4.0 \\
7.5\end{array}$ \\
\hline Centro-oeoidente & & 10.1 & 10.6 & 9.3 \\
\hline $\begin{array}{l}\text { Jalisoo } \\
\text { Colima } \\
\text { Nayarit } \\
\text { Aguracalientes } \\
\text { Zacateoas }\end{array}$ & $\begin{array}{r}15 \\
11 \\
19 \\
9 \\
29\end{array}$ & $\begin{array}{l}8.4 \\
0.0 \\
0.3 \\
0.5 \\
0.9\end{array}$ & $\begin{array}{l}7.7 \\
0.5 \\
0.4 \\
0.5 \\
1.5\end{array}$ & $\begin{array}{l}5.1 \\
1.2 \\
0.4 \\
0.3 \\
2.3\end{array}$ \\
\hline Noroeste & & 1.7 & 2.2 & 3.8 \\
\hline $\begin{array}{l}\text { Baja California Yorto } \\
\text { Baja California Sur } \\
\text { Sinaloa } \\
\text { Sonora } \\
\text { Durango }\end{array}$ & $\begin{array}{r}2 \\
88 \\
12 \\
5 \\
16\end{array}$ & $\begin{array}{l}0.2 \\
0 . \overline{3} \\
0.8 \\
0.4\end{array}$ & $\begin{array}{l}0.3 \\
0.7 \\
0.5 \\
0.7\end{array}$ & $\begin{array}{l}1.2 \\
0 . \overline{7} \\
0.6 \\
1.3\end{array}$ \\
\hline Norte-Nores te & & 5.2 & 3.4 & 4.1 \\
\hline $\begin{array}{l}\text { Chihuahua } \\
\text { Coahuila } \\
\text { Nuevo Le6́n } \\
\text { Tamaulipas }\end{array}$ & $\begin{array}{l}6 \\
4 \\
3 \\
7\end{array}$ & $\begin{array}{l}0.6 \\
1.8 \\
1.3 \\
1.5\end{array}$ & $\begin{array}{l}0.6 \\
1.3 \\
0.5 \\
1.0\end{array}$ & $\begin{array}{l}0.4 \\
0.8 \\
0.8 \\
2.1\end{array}$ \\
\hline Suresto & & 2.4 & 3.9 & 3.5 \\
\hline $\begin{array}{l}\text { Chiapas } \\
\text { Tabasoo } \\
\text { Campeche } \\
\text { urintana Ioo } \\
\text { Yuostan }\end{array}$ & $\begin{array}{l}31 \\
18 \\
13 \\
24 \\
14\end{array}$ & $\begin{array}{r}1.7 \\
\overline{-} \\
0 . \overline{7}\end{array}$ & $\begin{array}{l}1.0 \\
0.5 \\
0.3 \\
0.2 \\
1.9\end{array}$ & $\begin{array}{l}1.8 \\
0.9 \\
0.1 \\
0 . \overline{7}\end{array}$ \\
\hline $\begin{array}{l}\text { Total } \\
\text { Numera de casos }\end{array}$ & & $\begin{array}{r}99.7 \\
(608)\end{array}$ & $\begin{array}{c}100.1 \\
(1430)\end{array}$ & $\begin{array}{c}100.2 \\
\left(\begin{array}{ll}2 & 272\end{array}\right)\end{array}$ \\
\hline
\end{tabular}

Fuente: Muestra 'representativa ponderada.

a Rango en nivel de desarrollo socioeconómico en 1960; véase K. A. de Appendini et al., "Desarrollo desigual en México, 1900 y 1960", Demografí Y Economía, Vol. VI, Núm. 1, 1972, p. 20.

b Excluyendo los municipios correspondientes al área metropolitana de la ciudad de México (véase la nota 2 del apéndice).

gratorio de las entidades que la forman difiere también. La población proveniente de Guanajuato y Querétaro disminuye, mientras aumenta la que proviene de Michoacán, San Luis Potosí y Veracruz. Las dos primeras se encuentran en términos generales más cercanas a la ciudad 
Cuadro 3

Procedencia de la población no-Activa de la ciudad de México POR COHORTES DE LLEGADA A LA MISMA a

(Porcientos)

\begin{tabular}{|c|c|c|c|c|c|}
\hline \multirow[b]{2}{*}{ Zona $a^{b /}$} & \multicolumn{3}{|c|}{ Cohorter de Ilegada } & \multirow{2}{*}{ Tondenoia } & \multirow[b]{2}{*}{$\begin{array}{c}\text { Total } \\
(\%)\end{array}$} \\
\hline & $\begin{array}{c}\text { Antes } \\
\text { de } 1935\end{array}$ & $\begin{array}{l}1935- \\
1954\end{array}$ & $\begin{array}{l}1955- \\
1970\end{array}$ & & \\
\hline 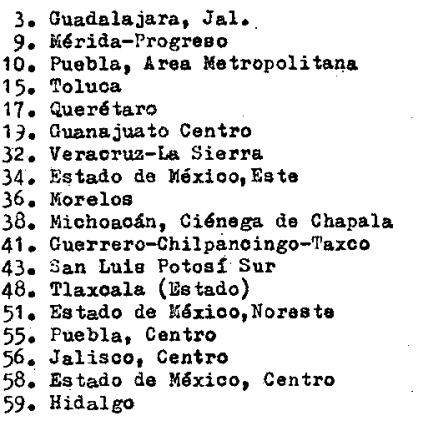 & $\begin{array}{l}4.5 \\
0.5 \\
4.1 \\
5.2 \\
2.2 \\
6.3 \\
1.2 \\
3.8 \\
2.0 \\
1.3 \\
1.5 \\
1.2 \\
3.9 \\
3.5 \\
1.8 \\
2.4 \\
4.1 \\
8.1\end{array}$ & $\begin{array}{l}3.3 \\
2.0 \\
4.0 \\
2.1 \\
1.3 \\
5.3 \\
2.1 \\
1.3 \\
1.9 \\
2.5 \\
1.2 \\
1.3 \\
2.5 \\
1.6 \\
2.0 \\
1.7 \\
3.5 \\
9.3\end{array}$ & $\begin{array}{l}1.7 \\
0.6 \\
2.0 \\
2.1 \\
0.4 \\
2.7 \\
3.0 \\
0.8 \\
2.0 \\
2.9 \\
0.8 \\
2.8 \\
2.5 \\
1.5 \\
2.4 \\
2.4 \\
2.2 \\
9.1\end{array}$ & 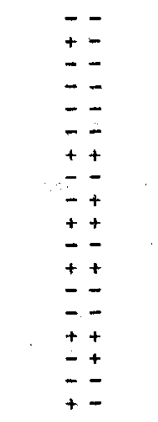 & $\begin{array}{l}2.6 \\
1.0 \\
2.9 \\
2.5 \\
1.0 \\
4.1 \\
2.4 \\
1.4 \\
1.9 \\
2.5 \\
1.0 \\
2.1 \\
2.7 \\
1.8 \\
2.2 \\
2.2 \\
2.9 \\
9.0\end{array}$ \\
\hline 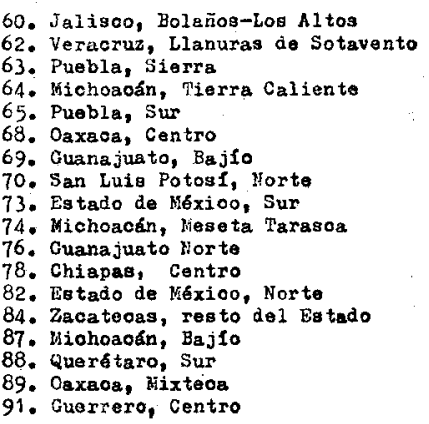 & $\begin{array}{l}1.0 \\
3.0 \\
1.8 \\
0.2 \\
0.8 \\
1.9 \\
3.3 \\
0.3 \\
2.0 \\
1.8 \\
2.5 \\
1.2 \\
5.3 \\
0.0 \\
1.0 \\
1.4 \\
0.0 \\
0.3\end{array}$ & $\begin{array}{l}2.1 \\
2.7 \\
2.1 \\
0.9 \\
1.7 \\
1.8 \\
4.9 \\
0.5 \\
1.3 \\
3.1 \\
2.3 \\
0.7 \\
3.4 \\
1.1 \\
1.7 \\
1.7 \\
2.5 \\
1.6\end{array}$ & $\begin{array}{l}1.0 \\
2.6 \\
2.3 \\
2.1 \\
2.0 \\
2.9 \\
5.2 \\
1.6 \\
1.1 \\
5.3 \\
1.2 \\
1.2 \\
2.1 \\
1.7 \\
0.9 \\
0.8 \\
1.9 \\
1.7\end{array}$ & 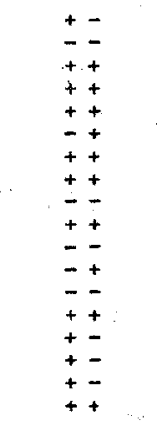 & $\begin{array}{l}1.4 \\
2.7 \\
2.2 \\
1.5 \\
1.7 \\
2.4 \\
4.8 \\
1.1 \\
1.3 \\
4.1 \\
4.7 \\
1.0 \\
3.0 \\
1.3 \\
1.1 \\
1.2 \\
1.8 \\
1.5\end{array}$ \\
\hline Total $(\%)$ & 85.5 & 85.0 & 79.5 & & 82.0 \\
\hline
\end{tabular}

a Se excluyen los lugares de donde procede menos del $1 \%$ de los no nativos.

b Las zonas se encuentran numeradas por orden decreciente de nivel de desarro-

llo socioeconómico. Sobre el cálculo de los niveles de desarrollo socioeconómico,

véase C. Stern, Las regiones de México y sus niveles de desarrollo socioeconómico, México, El Colegio de México, 1973. Se utiliza la zonificación de la Comisión Nacional de Salarios Mínimos correspondiente a 1963-1964. El total de zonas, que era de 111 , fue reducido a 98 mediante 19 agrupamientos que afectaran lo menos posible los niveles de desarrollo combinados.

c El signo $(-)$ representa disminuciones y el signo $(+)$ aumentos entre la proporción de migrantes de una cohorte a la siguiente.

capital y forman parte de una zona que ha registrado un proceso bastante dinámico de desarrollo industrial, en especial durante el último decenio.

La región periférica no urbanizada, cuya población fluye en proporciones crecientes hacia la capital, comprende dos de las entidades más atrasadas del país. 
Un análisis más detallado, a nivel de las zonas socioeconómicas de las que provienen los migrantes (sobre el cual no es posible extendernos en este trabajo), muestra que por lo general tienden a disminuir las proporciones de los migrantes que provienen de gran parte de las ciudades de tamaño intermedio (capitales regionales en su mayoría) y de zonas enmarcadas en regiones en las que se ha venido dando un proceso de industrialización más o menos destacado, mientras tienden a aumentar las que provienen de zonas rurales atrasadas. En el cuadro 3, se han ordenado, por orden decreciente de nivel de desarrollo socioeconómico las 36 zonas de las que proviene por lo menos el $1 \%$ de los migrantes que llegan a la capital, por cohortes de llegada.

Obviamente se requiere un estudio cuidadoso de las características de estas zonas y de los cambios que han sufrido en los últimos decenios; sin embargo, puede confirmarse la tendencia general descrita antes. Si agrupamos las zonas y denominamos a las primeras 18 como "más desarrolladas" y a las últimas 18 como las "menos desarrolladas", puede verse que entre las primeras predominan tendencias decrecientes, en términos de proporción de migrantes, mientras en las segundas predominan las tendencias crecientes, ${ }^{8}$ dándose también el caso de que entre las primeras se encuentra un número considerable de ciudades de cierto adelanto económico, mientras que entre las segundas predominan zonas agropecuarias atrasadas.

\section{Cuadro 4}

ORÍGENES DE LOS MIGRANTES INTERNOS POR TAMAÑO DE LA LOCALIDAD de nacimiento y por cohortes de llegada a la Cludad de México

(Porcientos)

\begin{tabular}{|c|c|c|c|c|c|c|}
\hline \multirow{2}{*}{$\begin{array}{l}\text { Tamaño de la } \\
\text { looalidad do } \\
\text { naoimlento } \\
\text { (habitantes) }\end{array}$} & \multicolumn{5}{|c|}{ Cohorte de llegada a la Ciudad de Máxico } & \multirow[b]{2}{*}{ Total } \\
\hline & $\begin{array}{c}\text { Antes } \\
\text { de } 1935\end{array}$ & $\begin{array}{l}1935- \\
1944\end{array}$ & $\begin{array}{l}1945- \\
1954\end{array}$ & $\begin{array}{l}1955- \\
1964\end{array}$ & $\begin{array}{l}1965- \\
1970\end{array}$ & \\
\hline Henos de 2500 & 27.4 & 31.7 & 34.2 & 36.4 & 40.0 & 34.9 \\
\hline $2500-4999$ & 13.9 & 8.4 & 13.5 & 14.5 & 13.3 & 13.2 \\
\hline $5000-19999$ & 21.1 & 24.2 & 16.0 & 17.6 & 15.5 & 18.1 \\
\hline $20000-99999$ & 24.0 & 18.7 & 18.9 & 16.6 & 13.2 & 17.6 \\
\hline $100000 \mathrm{~g}$ más & 4.6 & 5.9 & 6.7 & 6.9 & 4.8 & 5.9 \\
\hline Sin informacion & 3.0 & 11.0 & 10.7 & 8.0 & 13.2 & 10.2 \\
\hline $\begin{array}{l}\text { Némero de oasos en } \\
\text { muestra original }\end{array}$ & $(624)$ & $(536)$ & (895) & $\left(\begin{array}{ll}1 & 287\end{array}\right)$ & $(990)$ & $\left(\begin{array}{ll}4 & 332\end{array}\right)$ \\
\hline
\end{tabular}

Fuente: Muestra representativa ponderada.

8 Si se considera el sentido de cada uno de los cambios registrados entre las tres cohortes consignadas en el cuadro 3 , puede verse que entre las primeras 18 zonas existen 22 casos de disminución en la proporción de migrantes, 12 de aumento y 2 casos en que permanece constante, mientras que entre las segundas 18 zonas la situación es más o menos la inversa: 22 casos de aumento y 14 de disminución. 
III. ORIGEN DE LOS MIGRANTES POR TAMAÑos DE LA LOCALidAD Y POR NIVEL DE DESARROLlo SOCIOECONÓMICO DE LA ZONA DE NACIMIENTO

Es posible sistematizar la descripción de las tendencias esbozadas arriba cualitativamente en términos más específicos.

En el cuadro 4 puede verse la distribución de los migrantes internos por tamaño de la localidad de nacimiento y por cohortes de llegada a la ciudad, y en el cuadro 5, su distribución según niveles relativos de desarrollo socioeconómico de las zonas de origen de los mismos.

Los cuadros muestran con bastante claridad la existencia de una tendencia hacia el aumento de migrantes provenientes de localidades rurales y de zonas atrasadas. La proporción nacida en localidades menores de 2500 habitantes aumenta progresivamente de $27.4 \%$ para la cohorte que llegó a establecerse a la ciudad de México antes de 1935, hasta $40 \%$ para la que llegó después de 1965. Inversamente, mientras para la primera de las cohortes la población originaria de ciudades de

\section{Cuadro 5}

Orígenes DE LOS MigRANTES INTERNOS POR NIVEL DE DESARROLlo SOCIOECONÓMICO DE LA ZONA DE NACIMIENTO Y POR COHORTES de llegada A LA CIUDAd DE MÉxico

(Porcientos)

\begin{tabular}{|c|c|c|c|c|c|c|}
\hline \multirow{2}{*}{$\begin{array}{l}\text { Nivel do } \\
\text { desarrollog } \\
\text { do la sonu }\end{array}$} & \multicolumn{5}{|c|}{ Cohorto de llegada a la Ciudad de Moxioo } & \multirow{2}{*}{ Toṭal } \\
\hline & $\begin{array}{c}\text { Anten } \\
\text { de } 1935\end{array}$ & $\begin{array}{l}1935- \\
1944\end{array}$ & $\begin{array}{l}1945- \\
1954\end{array}$ & $\begin{array}{l}1955- \\
1964\end{array}$ & $\begin{array}{l}1965- \\
1970\end{array}$ & \\
\hline I (máa al to) & 5.6 & 8.7 & 5.5 & 5.9 & 2,1 & 5.3 \\
\hline II & 20.4 & 13.1 & 16.8 & 9.7 & 9.4 & 13.0 \\
\hline$\Pi \mathbf{I}$ & 5.2 & 6.0 & 4.9 & 7.0 & 7.6 & 6.3 \\
\hline $\mathbf{r v}$ & 11.4 & 11.0 & 9.4 & 14.0 & 9.9 & 11.4 \\
\hline $\mathbf{v}$ & 33.4 & 31.3 & 34.3 & 34.2 & 32.3 & 33.3 \\
\hline VI & 22.6 & 27.6 & 26.8 & 26.5 & 36.0 & 28.2 \\
\hline vII & 1.3 & 2.4 & 2.3 & 2.7 & 2.7 & 2.4 \\
\hline Número de 02808 & $(556)$ & $(483)$ & (832) & $\left(\begin{array}{ll}1 & 209\end{array}\right)$ & $(876)$ & (3956) \\
\hline
\end{tabular}

Fuente: Muestra representativa ponderada.

a Sobre el cálculo de los niveles de desarrollo socioeconómico, véase C. Stern Las regiones de México y sus niveles de desarrollo socioeconómico, México, El Colegio de México, 1973.

tamaño intermedio - de 20000 a 100000 habitantes - constituía el $24 \%$, dicha proporción disminuye en forma más o menos progresiva hasta llegar al $13.2 \%$ para la última.

Si distinguimos entre localidades rurales -menores de 5000 habitantes- y urbanas, puede verse que la población proveniente de las primeras aumenta de $41.2 \%$ a 53.3, mientras que la de las segundas disminuye de un $49.7 \%$ a $33.5 \% .^{\circ}$

9 Debe tomarse en cuenta que este proceso de "ruralización" de los migran- 
En relación al nivel de desarrollo relativo de las zonas de origen -véase el cuadro 5- puede comprobarse fácilmente la hipótesis sostenida, en términos generales. Dicotomizando entre las cuatro clases de zonas "más desarrolladas" y las restantes, puede verse que la población proveniente de las primeras representó un porciento de 42.6 para la primera cohorte de llegada considerada, disminuyendo a $29 \%$ para la última. Se observa también que, considerando todos las clases de niveles de desarrollo, existe una tendencia hacia la polarización creciente, disminuyendo el peso de la población proveniente de las clases de zonas más desarrolladas (I y II) y aumentando progresiva y sistemáticamente el de las más atrasadas (VI y VII), ya que entre las zonas correspondientes a las clases intermedias, las variaciones entre cohortes son más pequeñas y menos sistemáticas.

\section{RELACí́N DEL NIVEL DE INSTRUCCIÓN CON EL TAMAÑO DE LA LOCALIDAD Y EL NIVEL DE DESARROLLO SOCIOECONÓMICO DE LA ZONA DE NACIMIENTO}

Una vez demostrada nuestra primera hipótesis a nivel general, queda por mostrar que los niveles de instrucción de la población migrante se relacionan con el tamaño y con el nivel de desarrollo de su localidad y zona de nacimiento respectivamente.

\section{Cuadro 6}

Nivel de instrucción de la población adulta a de la ciudad de México POR TAMAÑO DE LA LOCALIDAD DE NACIMIENTO

\begin{tabular}{|c|c|c|c|c|c|c|c|c|}
\hline & \multicolumn{5}{|c|}{ Tamaño de la looalidad do naolmionto } & \multirow{2}{*}{$\begin{array}{c}\text { Ciudad da } \\
\text { M6rioo }\end{array}$} & \multirow[b]{2}{*}{ Extranjeros } & \multirow[b]{2}{*}{ Total } \\
\hline & -2500 & $\begin{array}{l}2500- \\
4999\end{array}$ & $\begin{array}{r}5000- \\
19999\end{array}$ & $\begin{array}{l}20000- \\
99999\end{array}$ & $100000+$ & & & \\
\hline $\begin{array}{l}\text { Promedio de años } \\
\text { de es tudio termi } \\
\text { nados }\end{array}$ & 3.1 & 3.8 & 4.7 & 5.5 & 5.1 & 6.1 & 8.7 & 5.1 \\
\hline $\begin{array}{l}\text { Dasviaolon } \\
\text { og tándar }\end{array}$ & 2.8 & 3.2 & 3.8 & 4.0 & 3.7 & 3.7 & 4.1 & 3.8 \\
\hline Núnero de casos & $\left(\begin{array}{ll}1 & 169\end{array}\right)$ & $(421)$ & $(609)$ & $(602)$ & (151) & $\left(\begin{array}{ll}2 & 483\end{array}\right)$ & (132) & $(5567)$ \\
\hline
\end{tabular}

Fuente: Muestra representativa no ponderada.

a Población mayor de 20 años que no asistía a centros de enseñanza en el momento de la encuesta (1970).

Sin entrar en mayores detalles, en los cuadros 6 y 7 se observa que las relaciones se presentan en la dirección esperada, cuanto menos en términos generales.

En el cuadro 6 puede verse que el número de años de estudio tiende a aumentar conforme aumenta el tamaño de la localidad de nates se ha dado en el contexto de un proceso acelerado de urbanización del país en su conjunto, por lo que adquiere mayor relevancia. En otras palabras, la "base" de la población rural ha disminuído en términos relativos a nivel nacional, mientras que la proporción de migrantes con orígenes rurales ha venido aumentando para el caso de la ciudad de México. 
Cuadro 7

Nivel de instrucción de la población Migrante AdUlta a de la ciudad DE MÉXICO SEgÚN NIVEL DE DESARROLLO DE LA ZONA DE NACIMIENTO

\begin{tabular}{|c|c|c|c|c|c|c|c|c|}
\hline & & Nivel & dogarrol & de la & na de & intents & & \\
\hline & VII & VI & $\mathrm{v}$ & $\mathrm{IV}$ & III & II & I & Total \\
\hline $\begin{array}{l}\text { Promedio de años do } \\
\text { os tudio terminados }\end{array}$ & 4.0 & 3.9 & 4.6 & 5.5 & 6.6 & 5.0 & 7.3 & 4.8 \\
\hline $\begin{array}{l}\text { Desviacion ostándar } \\
\text { Numero de casos }\end{array}$ & $\begin{array}{r}4.0 \\
(66)\end{array}$ & $\begin{array}{l}3.6 \\
(848)\end{array}$ & $\begin{array}{c}4.1 \\
(1010)\end{array}$ & $\begin{array}{c}4.0 \\
(287)\end{array}$ & $\begin{array}{c}4.6 \\
(182)\end{array}$ & $\begin{array}{c}4.2 \\
(383)\end{array}$ & $\begin{array}{c}4.3 \\
(165)\end{array}$ & $\begin{array}{c}4.1 \\
(2941)\end{array}$ \\
\hline
\end{tabular}

Fuente: Muestra representativa no ponderada.

a Población mayor de 20 años que no asistía a centros de enseñanza en el momento de la encuesta (1970).

cimiento, encontrándose diferencias cercanas a $50 \%$ entre los niveles de instrucción de aquellos nacidos en localidades menores de 2500 habitantes y aquellos nacidos en localidades de 20000 a 100000 habitantes.

Aun cuando la relación entre nivel de desarrollo socioeconómico de la zona de nacimiento y nivel de instrucción no se evidencía con claridad semejante a la anterior, el cuadro 7 muestra que los niveles de instrucción tienden a aumentar conforme aumenta el nivel de desarrollo socioeconómico de la zona (a pesar de que este último no se midió al momento de nacimiento sino a partir de datos más o menos recientes y de que muchas de las zonas comprenden tanto localidades urbanas como rurales). Con excepción de lo que ocurre con la población que proviene de las zonas comprendidas en la clase II, que muestran niveles de instrucción muy por debajo al que sería de esperar por el nivel de desarrollo socioeconómico con que cuentan, la relación entre nivel de instrucción y grado de desarrollo es bastante clara. ${ }^{10}$

\section{Niveles de instrucción de la población Migrante por COHORTES de llegada A LA CIUdAd dE MÉxico}

Habiendo mostrado que efectivamente se han dado cambios en los orígenes geográficos de los migrantes a la ciudad de México y que existe una relación entre dichos orígenes y el nivel de instrucción, queda por ver cómo se reflejan estos hechos en los niveles de instrucción de las diversas cohortes de migrantes según la época en que llegaron a la ciudad de México.

10 No tenemos elementos para explicar el caso desviado representado por el nivel educativo bajo de la población nacida en las zonas de la clase II. Podría tratarse de población con una estructura de edad más "envejecida", ya que esta clase de zonas incluye varias ciudades (como Toluca, Puebla y Querétaro) de las que solía venir una proporción importante de migrantes hace varios decenios, que disminuyó fuertemente en los últimos: Como el nivel educativo se encuentra inversamente relacionado con la edad (véase el cuadro 8) el bajo nivel de instrucción de la población proveniente de las zonas de la clase II podría deberse en parte a esta supuesta estructura por edad. 


\section{Cuadro 8}

Nivel de instrucción por cohortes de llegada a la ciudad de MÉxico, POR GRUPOS DE EDAD ACTUAL

(Promedio de años de estudio)

\begin{tabular}{|c|c|c|c|c|c|c|}
\hline \multirow[b]{2}{*}{ Grupos de odad } & \multicolumn{5}{|c|}{ Cohortes de llegada } & \multirow{2}{*}{$\begin{array}{c}\text { Mativos } \\
\text { del Area } \\
\text { Metropolitana }\end{array}$} \\
\hline & $\begin{array}{c}\text { Antes } \\
\text { de } 1935\end{array}$ & $\begin{array}{l}1935- \\
1944\end{array}$ & $\begin{array}{l}1945- \\
1954\end{array}$ & $\begin{array}{l}1955- \\
1964\end{array}$ & $\begin{array}{l}1965- \\
1970\end{array}$ & \\
\hline $\begin{array}{l}21-30 \\
\text { Kedia } \\
\text { Desviacion estandar } \\
\text { Namero de oasos }\end{array}$ & $\begin{array}{l}- \\
=\end{array}$ & $\begin{array}{l}\frac{7.3}{3.8} \\
(43)\end{array}$ & $\begin{array}{c}\frac{6.1}{3.8} \\
(251)\end{array}$ & $\begin{array}{r}\frac{5.3}{4.0} \\
(383)\end{array}$ & $\frac{5.0}{3.8}$ & $\begin{array}{r}8.0 \\
3.3 \\
(1036)\end{array}$ \\
\hline $\begin{array}{l}31-40 \\
\text { Yedia } \\
\text { Desviacion estandar } \\
\text { Humero de ossos }\end{array}$ & $\frac{6.2}{3.2}$ & $\frac{5.4}{4.4}$ & $\frac{4.8}{4.3}$ & $\frac{1.3}{3.8}$ & $\begin{array}{r}5.0 \\
4.4\end{array}$ & $\begin{array}{c}7.6 \\
4.0 \\
(617)\end{array}$ \\
\hline $\begin{array}{l}41-50 \\
\text { Media } \\
\text { Desvizoion eaténdar } \\
\text { Nanero do oagos }\end{array}$ & $\begin{array}{l}\frac{5.6}{4 \cdot 5} \\
(114)\end{array}$ & $\frac{4.4}{3.9}$ & $\frac{4.6}{4.0}$ & $\frac{4.0}{4.0}$ & $\frac{3.0}{2.8}$ & $\begin{array}{c}6.6 \\
4.0 \\
(371)\end{array}$ \\
\hline $\begin{array}{l}51-60 \\
\text { Media } \\
\text { Desviaoión estándar } \\
\text { Número de osaos }\end{array}$ & $\begin{array}{l}\frac{4.6}{4.3} \\
(228)\end{array}$ & $\frac{4.2}{3.5}$ & $\frac{5.0}{4.2}$ & $\frac{4.4}{4.1}$ & $\frac{2.8}{4.5}$ & $\begin{array}{c}6.2 \\
3.9 \\
(194)\end{array}$ \\
\hline $\begin{array}{l}60+ \\
\text { Kedia } \\
\text { Degviaoión estándar } \\
\text { Mamero de casos }\end{array}$ & $\frac{3.4}{3.7}$ & $\frac{1.1}{4.0}$ & $\frac{3.8}{4.3}$ & $\frac{1.9}{2.7}$ & $\begin{array}{l}\frac{1.6}{2.8} \\
(14)\end{array}$ & $\begin{array}{c}4.7 \\
3.4 \\
(132)\end{array}$ \\
\hline
\end{tabular}

Fuente: Muestra representativa no ponderada.

Dada la estructura por edades de las diversas cohortes de migrantes y la relación inversa entre edad y nivel de instrucción, sería de esperarse que las cohortes más recientes, en las que predominan los migrantes actualmente jóvenes, contaran con niveles de instrucción sensiblemente mayores, en promedio, que las cohortes anteriores.

Sin embargo, pensamos que orígenes más "rurales" y "subdesarro1lados" de las cohortes más recientes operan en sentido inverso, llevándonos a hipotetizar incluso una disminución de los promedios generales de nivel de instrucción de los migrantes.

El cuadro 8 muestra que tal deterioro efectivamente se ha venido presentando. Para cada uno de los grupos de edad se observa una tendencia hacia la disminución de los niveles de instrucción de los migrantes, ${ }^{11}$ lo cual obviamente se traduce en un distanciamiento cada vez mayor con respecto a los promedios educativos de la población nativa.

En términos generales, los resultados anteriores darían apoyo a la hipótesis según la cual la creciente marginalidad ocupacional de los migrantes en la ciudad de México se debe, cuando menos en parte, al

11 Las desviaciones que se presentan a esta tendencia, en especial la de los migrantes más recientes del grupo de 31 a 40 años de edad, ameritan un análisis mayor. Datos preliminares permiten inferir que para dicho caso particular se trata en su mayor parte de migrantes provenientes de ciudades de tamaño intermedio que probablemente han migrado para continuar carreras ocupacionales en ascenso. 
deficiente nivel de instrucción con que llegan a la ciudad proporciones importantes de ellos.

\section{RESUMEN E INTERPRETACión}

Partiendo de un evidente deterioro en los niveles de ocupación de sectores crecientes de la población migrante a la ciudad de México, habíamos propuesto que parte de la explicación podría encontrarse en supuestos cambios de los flujos migratorios que se han dirigido hacia la capital en los últimos decenios. Habíamos supuesto que los mrigrantes tienden a provenir crecientemente de localidad rurales y de zonas atrasadas, lo cual habría de reflejarse en que tuvieran niveles decrecientes de educación formal.

Pensamos que el análisis preliminar desarrollado en este trabajo permite apoyar dichas hipótesis en términos generales. Obviamente se requiere un análisis más cuidadoso de la información presentada así como de información adicional que nos encontramos elaborando.

Por una parte, antes de llegar a conclusiones definitivas debe especificarse la relación inversa encontrada entre fecha de llegada y nivel de instrucción, introduciendo una serie de variables adicionales, tales como sexo, edad de llegada a la ciudad de México y tamaño de la localidad de origen. Es posible que la interacción de algunas de estas variables modifique los resultados iniciales a que hemos llegado.

Por otra parte será necesario, una vez conocidos los resultados del análisis anterior, hacer un estudio bastante detallado de la dinámica regional que los está produciendo. Podríamos preguntarnos, por ejemplo, sobre las causas de las modificaciones en los orígenes regionales y comunales de las personas que migran a la ciudad de México. ¿Se trata de que las zonas más desarrolladas y las localidades urbanas en general han continuado desarrollándose y por lo tanto "envían" menos migrantes a la ciudad de México? Y las zonas menos desarrolladas, ¿envían mayores contingentes de migrantes debido a su estancamiento o debido a un proceso de cambio que expulsa población? ¿o se trata simplemente del proceso más o menos universal de una disminución en la selectividad de los migrantes, en otras palabras, de que antes migraban solamente las personas más capacitadas y con mayores recursos, debido al riesgo implicado y a las dificultades de comunicación exis. tentes, mientras que ahora la disponibilidad a la migración se generaliza cada vez más debido a la mayor facilidad que existe para ella? ${ }^{12}$

Por lo pronto no tenemos elementos suficientes para contestar a

12 Véanse los trabajos de Harley L. Browning, "Migrant Selectivity and the Growth of Large Cities in Developing Societies", en Rapid Population Growth, Consequences and Policy Implications, National Academy of Sciences, Baltimore, Johns Hopkins, 1971 y, del mismo autor en colaboración con Waltraut Feindt, "Selectividad de migrantes a una metrópoli en un país en desarrollo: estudio de un caso mexicano", en Demografía Y Economía, Vol. III, núm. 2, 1969, pp. 186-200. 
éstas y otras preguntas de gran interés relacionadas con los problemas del crecimiento urbano, la marginalidad, y el proceso de cambio que está acaeciendo y que tan directa y visiblemente afecta a grandes contingentes de la población, pero pensamos que el tipo de análisis que nos encontramos realizando es un paso necesario para aclarar mejor estos procesos y acercarnos a la respuesta de algunas de estas preguntas.

\section{APÉNDICE METODOLÓGICO}

1. Los datos utilizados en este trabajo provienen de una muestra estratificada y representativa de la población del área metropolitaná de la ciudad de México. La encuesta sobre algunas características de los 13000 habitantes de 2500 viviendas fue llevada a cabo entre noviembre de 1969 y febrero de 1970. Los datos que aquí se presentan corresponden a las estimaciones del universo realizadas mediante una expansión ponderada de los datos de la muestra original; sin embargo, se incluyen al pie de cada cuadro los marginales de la muestra original para que el lector cuente con bases que le permitan evaluar los datos.

2. El área metropolitana de la ciudad de México comprende, además del Distrito Federal, los municipios de Chimalhuacán, Ecatepec, Naucalpan, Tlalnepantla y Netzahualcóyotl del Estado de México.1

3. Para fines de este trabajo se define como migrante toda persona nacida fuera de lo que ha sido definido para 1970 como área metropolitana de la ciudad de México. La configuración de ésta varía a través del tiempo, hecho que no ha sido tomado en cuenta para este análisis preliminar. En otras palabras, algunas personas no consideradas aquí como migrantes lo serían si se adoptaran diferentes definiciones del área metropolitana según las distintas etapas de llegada.

4. Conceptualmente sería más adecuado trabajar con la comunidad de origen (aquella en la que el individuo pasó la mayor parte del tiempo entre los 5 y los 15 años de edad) que con la localidad de nacimiento, para distinguir entre migrantes y nativos. ${ }^{2}$ De acuerdo con datos indirectos, probablemente entre un 30 y un $40 \%$ de los migrantes tuvieron como comunidad de orgien una localidad de tamaño diferente al de su localidad de nacimiento, y en muchos casos tuvieron como comunidad de origen la propia ciudad de México, habiendo migrado cuando niños a la misma. Estos hechos seguramente tienen influencia sobre las oportunidades educacionales de los migrantes. Los datos de los cuales partimos para este análisis preliminar, sin embargo, no nos permiten trabajar con la comunidad de origen, la cual no fue captada en esta primera encuesta. Posteriormente incorporaremos información adicional al análisis, con base en encuestas realizadas en una segunda etapa de la investigación.

1 Para la delimitación del área metropolitana de la ciudad de México véase Luis Unikel, "La dinámica del crecimiento de la ciudad de México", Comercio Exterior, Vol. XXI, Núm. 6, junio de 1971. En el trabajo nos referiremos indistintamente al área metropolitana de la ciudad de México como área metropolitana, como ciudad de México o como capital del país.

2 Para fundamentar la importancia de esta distinción véase Harley L. Browning y W. Feindt, "Diferencias entre la población nativa y la migrante en Monterrey”, México, Demografía y Economía, Vol. II, núm. 2, 5, 1968, p. 186. 
5. El tamaño de la localidad de nacimiento corresponde al reportado en el censo de población más cercano a la fecha de nacimiento.

6. El nivel de desarrollo socioeconómico de las zonas fue calculado con base en datos correspondientes a 1960 y 1965 y consiste de un índice compuesto computado a partir de cuatro variables: proporción de población urbana, proporción de población dedicada a actividades secundarias, proporción de población dedicada a actividades terciarias, e ingreso promedio por trabajador ocupado. ${ }^{3}$ No han sido calculados niveles de desarrollo relativo correspondientes a períodos anteriores. Suponer que los niveles de desarrollo existentes en el decenio de los sesenta, a nivel de zonas relativamente pequeñas (su número es de 111), son aplicables a períodos históricos anteriores es insostenible. El supuesto inevitable que manejamos es que las variaciones de nivel de desarrollo relativo de las zonas no han sido tantas en los últimos decenios como para invalidar los resultados generales. ${ }^{4}$

7. Las tendencias en términos de cambios en la composición de los flujos migratorios se infieren a partir de observaciones sobre los migrantes sobrevivientes en la ciudad de México en 1970, divididos por cohortes de llegada a la misma (de acuerdo con la fecha reportada como última llegada para establecerse en la capital). El supuesto implicito es que las cohortes sobrevivientes constituyen una muestra adecuada de las cohortes que efectivamente llegaron a establecerse. De hecho es probable que se den diferencias en variables tales como esperanza de vida, propensión a la migración de retorno, etc., entre grupos con características distintas en términos de edad, origen rural o urbano, etc., que hagan que la muestra de migrantes sobrevivientes no sea totalmente "representativa" de los migrantes que efectivamente llegaron a establecerse. Se supone nuevamente que dicho sesgo no es de importancia suficiente como para invalidar los resultados.

8. Los cortes efectuados para definir las cohortes de llegada -.antes de 1935, 1935-1944,1945-1954, 1955-1964, 1965-1970- no son del todo arbitarios y pretenden reflejar cortes paralelos en el proceso de desarrollo socioeconómico tanto de la ciudad como del país en general. El periodo que va de 1910 a 1935 abarca tanto la revolución armada como su consolidación institucional. Aparte de desajustes ecunómicos internos comprende la era de la gran depresión. Sólo con posterioridad lograron igualarse los indicadores de desarrollo económico a los existentes al inicio de la revolución. La ciudad de México creció lentamente (cuando menos en comparación con lo que vendría después), sirviendo como refugio a parte de la élite provincial que huía de la inseguridad. El período de 1935 a 1944 comprende la era cardenista y la segunda guerra mundial. Se inicia el auge de la industrialización y

3 Véase Claudio Stern, Las regiones de México y sus niveles de desarrollo socioeconómico, México, El Colegio de México, 1973. El autor reconoce las limitaciones del índice para medir concepto tan complejo, en especial su sesgo hacia reflejar niveles de desarrollo urbano más bien que agropecuario; sin embargo no existe ningún otro índice calculado.

4 Estudios de niveles de desarrollo relativo a nivel estatal muestran que los rangos de la mayor parte de las entidades han variado poco entre 1900 y 1960. Véase Kirsten A. de Appendini et. al., "Desarrollo desigual en México, 1900 y 1960”, Demografía y Economía, Vol. VI, núm. 1, 1972, p. 20. 
se llevan a cabo grandes transformaciones en el agro y en la infraestructura económica en general. Se dinamiza aceleradamente el desarrollo industrial de la capital, el cual requiere de grandes volúmenes de mano de obra, lo que se refleja en un crecimiento muy acelerado de la población de la misma. En el periodo de 1945 a 1954 continúa en términos generales el "auge" económico generado en la etapa anterior y la ciudad sigue creciendo aceleradamente. El "modelo" de desarrollo se define dando una clara prioridad al proceso de industrialización en detrimento de la población campesina. Sin embargo, la producción agrícola continúa creciendo, con base fundamentalmente en unas cuantas áreas altamente capitalizadas del norte del país. Para 1955 hay signos indudables de una disminución en el ritmo de crecimiento así como de importantes estrechamientos para la continuación de un proceso de desarrollo acelerado con estabilidad. En el decenio siguiente disminuye la capacidad del sector industrial para absorber a la creciente fuerza de trabajo; se deterioran las condiciones en el campo y empeora la distribución del ingreso. En 1964 se "cierra" la frontera norteamericana a los buscadores de trabajo mexicanos. Se intensifica la migración interna hacia la capital, haciéndose claramente visible una creciente marginalidad $5^{5}$

9. El hecho de que la primera cohorte considerada sea acumulativa (migrantes sobrevivientes que llegaron al área metropolitan antes de 1935) y que la última cohorte corresponda a un periodo de llegada que abarca cinco años en lugar de diez como las anteriores, deben tomarse en cuenta al juzgar los resultados del presente análisis. Probablemente si se hicieran cortes diferentes se encontrarían variacions con respecto a los resultados aquí obtenidos: Sin embargo, conviene enfatizar que por el momento el objetivo es encontrar tendencias generales, las cuales no creemos se verían modificadas por el hecho de hacer los cortes en otros puntos.

Merecen mayor precaución las evaluaciones que hagamos con respecto a las magnitudes que presenten la primera y la última cohorte, las cuales pueden considerarse como menos "representativas", la primera por su carácter acumulativo, en la cual se mezclan seguramente tendencias bastante diversas correspondientes a diferentes momentos históricos, y la última por lo reciente de la migración de la misma. Sería sensato suponer, por ejemplo, que la proporción de migrantes de esta última cohorte que permanecerán en el área metropolitana sea un poco menor que la correspondiente a las cohortes anteriores, si pensamos que las probabilidades de fracaso y de retorno son bastante mayores en los primeros años de intento de integración al medio urbano-industrial que cuando el migrante ya ha estado establecido en dicho medio por un período prolongado. Igualmente, sería sensato esperar que la mayor proporción de migrantes recientes que no permanezcan en el área metropolitana corresponda a los migrantes rurales, los cuales probablemente tengan mayores probabilidades de fracasar que los migrantes urbanos.

5 El presente esbozo requiere una mayor justificación y evidentemente no pretende gran exactitud, sino una aproximación con las tendencias macro-estructurales que se han presentado en el país. 
10. Una evaluación de lo que significan las tendencias analizadas en este trabajo, correspondientes a algunos fenómenos relacionados con la inmigración al área metropolitana, en términos de la dinámica regional del país, requiere obviamente del análisis de factores relacionados con tasas y modalidades de emigración a partir de las "zonas de rechazo", por llamarles de alguna manera. En otras palabras, de ningún modo se pretende que a partir de los datos aquí analizados puedan sacarse conclusiones con respecto a la dinámica migratoria del país en su conjunto, o de cualquiera de sus regiones. El que una proporción menor de gente venga de determinadas zonas, por ejemplo, no implica que la emigración a partir de dichas zonas haya disminuido; puede ser que los flujos migratorios a partir de dichas zonas se dirijan ahora hacia otra parte, o simplemente que el volumen o la proporción de migrantes que vienen de otras zonas haya aumentado, restándole peso relativo a la inmigración proveniente de las primeras.

11. Hemos tomado como indicador de educación el promedio de años de estudio formal terminados y aprobados por la población adulta que ya no asiste a centros de enseñanza. E1 promedio de años de estudio no es una medida muy eficiente debido a que presenta una dispersión relativamente elevada; a pesar de ello, es la única variable que nos permite tener una indicación global y comparable de los niveles medios de educación de la población con la cual tratamos. En los cuadros respectivos se presentan los datos correspondientes a la muestra original, ya que pensamos que la ponderación de los mismos en términos de la población total del área metropolitana no resultaría útil en este caso. Incluimos también el dato de la desviación estándar de cada promedio, para que el lector esté en posibilidad de evaluar mejor los datos.

La decisión de tomar en cuenta únicamente a la población mayor de veinte años que no asiste a centros de enseñanza en el momento de la encuesta, se debe a que pensamos refleja mejor los niveles de instrucción finalmente logrados por la población. 